\title{
As lutas feministas e suas reverberações na arte: das práticas sócio-políticas à teoria crítica feminista
}

\author{
Las luchas feministas y sus reverberaciones en el arte: de las prácticas \\ socio-políticas a la teoría crítica feminista
}
Feminist struggles and their reverberations in art: from sociopolitical practices to feminist critical theory

\author{
Juliana Aparecida dos Santos Miranda ${ }^{1}$
}

\begin{abstract}
Resumo
O artigo a seguir caminha sobre as linhas dos estudos da crítica cultural e da teoria crítica feminista, através de uma metodologia qualitativa, a fim de refletir acerca do movimento feminista e da sua contribuição para os fazeres artísticos de mulheres, mais especificamente a literatura. Nesse contexto, este artigo tratará sobre a organização do feminismo enquanto movimento social e movimento político, refazendo o percurso das ondas feministas e refletindo sobre suas conquistas. A seguir, a literatura passa a ser objeto de análise. Nesse momento a discussão estará em torno da noção de literatura feminina e suas contradições, bem como na reflexão sobre os trabalhos de revisão que permitem que a literatura seja um espaço de ressignificação identitária da mulher.
\end{abstract}

Palavras-Chave: Crítica Cultural; Crítica feminista; Feminismo; Literatura feminina; Mulheres.

\section{Resumen}

El artículo siguiente camina sobre las líneas de los estudios de la crítica cultural y de la teoría crítica feminista, a través de una metodología cualitativa, a fin de reflexionar acerca del movimiento feminista y de su contribución a los hechos artísticos de mujeres, más específicamente a la literatura. En este contexto, este artículo tratará sobre la organización del feminismo como movimiento social y movimiento político, rehaciendo el recorrido de las ondas feministas y reflexionando sobre sus conquistas. A continuación, la literatura pasa a ser objeto de análisis. En ese momento la discusión estará en torno a la noción de literatura femenina y sus contradicciones, así como en la reflexión sobre los trabajos de revisión que permiten que la literatura sea un espacio de resignificación identitaria de la mujer.

Palabras Clave: Crítica Cultural; Crítica feminista; Feminismo; Literatura femenina; Mujeres.

\begin{abstract}
The following article focuses on the lines of the studies of cultural criticism and critical feminist theory, through a qualitative methodology, in order to reflect on the feminist movement and its contribution to the artistic practices of women, more specifically literature. In this context, this article will deal with the organization of feminism as a social movement and political movement, retracing the course of feminist waves and reflecting on their achievements. The literature is then analyzed. In this moment the discussion will be around the notion of feminine literature and its contradictions, as well as in the reflection on the works of revision that allow the literature to be a space of feminine identity resignification.
\end{abstract}

Keywords: Cultural Criticism; Feminist criticism; Feminism; Women's literature; Women.

1 Mestra em Crítica Cultural; Universidade do Estado da Bahia; Salvador, Bahia, Brasil; julianasanmi@gmail.com. 
O feminismo, enquanto movimento organizado, faz parte da história de lutas no mundo desde a Revolução Francesa, no século XVIII. Desse período até os dias atuais, as conquistas femininas no âmbito social, político e cultural se deram através das inúmeras manifestações de mulheres que enfrentaram os poderes hegemônicos patriarcais a fim de construir uma sociedade mais justa e igualitária para as mulheres. O movimento organizado de mulheres mais conhecido, que se espalhou mundialmente entre o final do século XIX e o início do século XX, foi o movimento sufragista, em que a luta consistia em obter direitos eleitorais, para que assim as mulheres pudessem votar e serem votadas. No Brasil, ao longo da década de 1920, o movimento sufragista esteve fortemente associado ao nome da bióloga Bertha Lutz.

O sufragismo brasileiro representou apenas uma parcela do que foi o movimento feminista no Brasil; além dele outros movimentos de mulheres, alguns organizados e outros militâncias individuais, contribuíram para o fortalecimento do pensamento feminista no país. De acordo com Céli Regina Pinto (2003), o movimento feminista no Brasil das primeiras décadas do século XX pode ser observado através de três diferentes vertentes. A primeira vertente aponta para um feminismo que a autora define como sendo bem-comportado. Nesse momento, a proposta era incluir as mulheres politicamente na sociedade sem questionar, entretanto, o lugar do homem. A segunda vertente, Céli Regina Pinto define como feminismo difuso, nesse contexto, houve a defesa da educação das mulheres, do direito da livre sexualidade e do divórcio e começa-se a questionar a dominação do homem sobre a mulher. A terceira a vertente estava ligada ao movimento anarquista, em que as mulheres trabalhadoras, intelectuais e militantes dos movimentos de esquerda agiam em defesa da libertação total das mulheres a qualquer custo.

O feminismo no Brasil durante a década de 1960 apresentou-se, em paralelo com as lutas feministas de outros países, sob o contexto de períodos de guerra e pós-guerra e sob a promessa de prosperidade econômica norte-americana. Entretanto, enquanto a sociedade mundial começava a se reorganizar em torno dos valores familiares, limitando o espaço da mulher ao âmbito doméstico, o Brasil encontrava-se em efervescência política causada pelo golpe militar de 1964 (PINTO, 2003). Em um regime que cada vez mais se aproximava ao totalitarismo, o Brasil experimentou uma política anti-democrática baseada, sobretudo, no cerceamento da liberdade de expressão e na censura de costumes e morais. Mesmo sob tais repressões políticas, foi neste período que os movimentos de mulheres começaram a eclodir 
no país, bem como o feminismo começou a se desenvolver enquanto movimento político. Assim, movimentos como os que lutavam contra a carestia dos preços, a favor da criação de creches e o movimento de mulheres pela anistia foram alguns dos que marcaram a entrada de mulheres da classe operária e donas de casa na luta pelos direitos das mulheres.

De acordo com Céli Regina Pinto,

O feminismo brasileiro nasceu e se desenvolveu em um dificílimo paradoxo: ao mesmo tempo que teve de administrar as tensões entre uma perspectiva autonomista e sua profunda ligação com a luta contra a ditadura militar no Brasil, foi visto pelos integrantes desta mesma luta como um sério desvio pequeno-burguês (PINTO, 2003, p. 45).

A evidência posta pela estudiosa revela muito sobre como os espaços políticos, compostos basicamente por homens, consideravam importante a presença das mulheres, principalmente no que se refere aos movimentos de esquerda, mas ignoravam de forma contundente a luta das mulheres pela própria emancipação. Deste modo, o que se esperava era que a luta contra o fim da ditadura militar fosse primordialmente o principal interesse das mulheres militantes, enquanto uma enorme negligência se estendia em relação aos problemas que afetavam a vida exclusivamente das mulheres. Os problemas das mulheres estavam sempre sendo tratados como menores e, por este motivo, o feminismo era tido como um desvio pequeno-burguês, que fragmentava a luta por soluções para os problemas ditos gerais. Ao desassociar as questões inerentes das mulheres do processo de libertação do povo, cai-se na armadilha de acreditar, erroneamente, que existe democracia sem a participação das mulheres.

A partir da década de 1970 o movimento feminista brasileiro começou a ganhar força política e, com isso, passam a ocorrer com frequência atividades públicas importantes, a exemplo do congresso promovido pelo Conselho Nacional da Mulher, em 1972. Entre as décadas de 1970 e 1980 cresceu muito o número de mulheres que se identificavam com o feminismo e promoviam reuniões com grupos de reflexão e discussão sobre os problemas enfrentados pelas mulheres. A maioria dessas mulheres estavam divididas entre dois partidos políticos, o PT e o PMDB, o que permitiu que o debate fosse levado de fato para a esfera política, ao mesmo tempo em que favorecia uma possível dissolução do movimento. Além disso, o feminismo, enquanto movimento político, ainda não era totalmente aceito nem pelos partidos de esquerda, muito menos pelos de direita, uma vez que a esquerda via no feminismo uma ameaça à unidade da luta do proletariado contra o capitalismo, e a direita acusava o feminismo de destruir a moral, os bons costumes e a unidade familiar. 
O ano de 1975 foi um marco na história do movimento feminista no Brasil. Apesar dos avanços conquistados desde o início da década, muitas questões importantes para as mulheres ainda eram negligenciadas pelo governo ditador. Uma proposta da ONU em evidenciar as discussões acerca dos direitos das mulheres em várias partes do mundo fez de 1975 o Ano Internacional da Mulher. De acordo com Maria Amélia de Almeida Teles, as "mulheres dos países europeus e norte-americanos viam com desconfiança a iniciativa da ONU, no Brasil ela cai como uma luva: excelente instrumento legal para fazer algo público, fora dos pequenos círculos de ações clandestinas" (TELLES, 1999, p. 85). A parceria das militantes feministas brasileiras e da ONU permitiu que as pautas discutidas em reuniões privadas ou até mesmo em espaços públicos de pouco acesso popular ressonasse numa proporção maior e mais estruturada. Assim, “a questão da mulher ganhava a partir daí um novo status, tanto diante de governos autoritários e sociedades conservadoras como em relação a projetos ditos progressistas" (PINTO, 2003, p. 56).

Além disso, outros encontros importantes para a agenda feminista se concretizaram no ano de 1975. Entre eles estão o $1^{\circ}$ Encontro de Mulheres do Rio de Janeiro, que deu origem à formação do Centro da Mulher Brasileira; o Encontro para o Diagnóstico da Mulher Paulista, que deu origem ao Centro de Desenvolvimento da Mulher Brasileira; a reunião anual da Sociedade Brasileira para o Progresso da Ciência (SBPC), que incentivava o feminismo acadêmico; e a organização do Movimento Feminino pela Anistia, que buscava anistia para os presos ou exilados políticos. Ainda nesse ano, a imprensa feminista também deu um salto em direção ao avanço através da publicação da primeira e segunda edição do jornal Brasil Mulher. O primeiro editorial do Brasil Mulher não deixava dúvidas sobre o cunho feminista da publicação, embora o termo feminista só passasse a ser utilizado pelo jornal a partir do ano seguinte: “(...) Queremos falar dos problemas que são comuns a todas as mulheres do mundo. Queremos falar também das soluções encontradas aqui e em lugares distantes; no entanto queremos discuti-las em função da nossa realidade brasileira e latino-americana (...)" (TELES, 1999, p. 87). Em 1976, outro jornal importante para o feminismo no Brasil surge, o jornal Nós Mulheres, cuja proposta fundamental era promover debates nas escolas e bairros da periferia, sempre servindo aos interesses das mulheres das camadas mais populares da sociedade.

Na década seguinte, 1980, o Brasil entrou em processo de redemocratização e com isso vieram a reforma partidária e a anistia aos presos e exilados políticos. Esse momento foi o início de um período com menos repressão e com mais abertura para manifestações públicas. Isso possibilitou a ampliação de organizações feministas e uma agenda que abrangia 
uma diversidade maior de reivindicações. Neste contexto, as feministas se dividiram em dois grupos de forte expressão, "de um lado ficaram as que lutavam pela institucionalização do movimento e por uma aproximação da esfera estatal e, do outro, as autonomistas que viam nessa aproximação um sinal de cooptação" (PINTO, 2003, p. 68). Ao fim, a institucionalização do feminismo acabou por ocorrer e feministas passaram a representar as mulheres juntamente ao Estado.

A entrada oficial das feministas em partidos políticos possibilitou que as reivindicações sobre as legislações para as mulheres fossem efetivadas. Com isso, exigia-se que novas leis fossem inseridas na Constituição de 1988, leis que abrangessem os direitos femininos em sua amplitude. Assim, conforme afirma Eva Blay, mulheres de diversas vertentes feministas se uniram a fim de pressionar o Estado "pela aprovação da igualdade constitucional entre homens e mulheres, no casamento, na relação com os filhos e aos bens materiais" (BLAY, 2017, p. 88). Ainda de acordo com a estudiosa, muitas das reivindicações foram atendidas, mas questões relacionadas aos direitos reprodutivos das mulheres, principalmente ao que diz respeito ao aborto, sofreram, ao invés de avanços, retrocessos. Isso se deve, sobretudo, aos grupos religiosos e conservadores. Outro avanço permitido pela redemocratização foi a participação das mulheres pertencentes à minoria política, a exemplo de mulheres LBTTs $^{2}$ e das mulheres negras, que passaram a ter espaços para impor as suas reivindicações.

Neste momento, a pauta acerca da saúde das mulheres, especialmente sobre a questão da conscientização e do enfrentamento à AIDS, passou por significativos avanços. A questão da violência contra a mulher passou a receber maior atenção por parte do Estado. Ainda no final da década de 1970 pensava-se na violência contra a mulher como fundamentalmente resultado das dificuldades econômicas, assim, a questão era vista como uma ramificação da violência capitalista contra os homens, sob o argumento de que "[...] o cansaço, a bebida e a exploração capitalista justificariam a agressão contra a mulher, a própria companheira, e isso não deveria ser punido" (BLAY, 2017, p. 83), ou então que "somente os homens negros e pobres espancavam as mulheres, devido ao alcoolismo e à extrema pobreza" (TELLES, 1999, p. 131). Em 1976, o crime de assassinato cometido contra a modelo Leila Diniz, pelo seu companheiro Doca Street, fez com que o mito sobre a violência contra as mulheres ter razões estritamente econômicas começasse a se desfazer.

2 Sigla para fazer referência às mulheres Lésbicas, Bissexuais, Transexuais e Travestis. O elemento "G", que diz respeito a homens gays, foi retirado, uma vez que estamos tratando da questão específica das mulheres. 
A partir da década de 1980, medidas concretas começaram a ser tomadas a fim de incentivar as denúncias e inibir as agressões. Diversas organizações se formaram em função desta causa, sendo a primeira delas a SOS Mulher, fundada no Rio de Janeiro em 1981. Com a criação da Delegacia de Defesa da Mulher, em 1985, os casos de violências, principalmente as de cunho doméstico, começaram a ser expostos, levando à tona uma realidade até então ocultada. De acordo com Maria Amélia Telles (1999, p. 137), entre agosto e dezembro do ano de 1986, somente na cidade de São Paulo, foram registrados em torno de 2.038 boletins de ocorrência; desse número, 71,3\% eram de mulheres que denunciavam seus companheiros por agressão física. Os resultados conquistados através da Delegacia de Defesa da Mulher foram tão evidentes que ela se popularizou e se espalhou pelo país; até o ano de 2016, somavam o número de $462^{3}$ delegacias especializadas difundidas pelo Brasil. Embora as delegacias não resolvam definitivamente o problema da violência contra a mulher, a sua contribuição é fundamental para que as mulheres agredidas se reconheçam enquanto vítimas e, deste modo, passem a denunciar seus agressores para que haja a chance de eles serem devidamente punidos.

Teoricamente, considerando os anos de lutas do feminismo no Brasil e as suas importantes conquistas para as mulheres, na década de 1990 o feminismo estaria totalmente consolidado. No entanto, algumas questões fizeram com ele entrasse em uma zona de ambiguidade que revelava ainda haver embates a serem enfrentados: de um lado surgiam movimentos anti-feministas e começava-se a discutir a ideia do pós-feminismo; por outro, uma militância difusa e generalizada se popularizava fora da esfera político-partidária. Apesar desse retraimento do movimento feminista durante esse período (PINTO, 2003, p. 92), é possível observar o modo como o pensamento feminista incorporou-se nos discursos e nas ações de uma parcela da população brasileira, promovendo mudanças significativas no modo como a sociedade lida com temáticas acerca das minorias sociais. Céli Regina Pinto exemplifica: “[...] um exemplo muito transparente e facilmente verificável é a diminuição do espaço de legitimidade para piadas e anedotas racistas, machistas e que ridicularizem o homossexual, principalmente o masculino" (PINTO, 2003, p. 92).

Além dessa mudança nas esferas populares, as pautas das agendas feministas estavam sendo abordadas em campanhas eleitorais; com isso, os direitos das mulheres eram discutidos

3 Embora esse seja o número oficial registrados pelo Governo Federal, pesquisadoras da revista eletrônica Azminas relatam haver divergências nos números, uma vez que algumas das delegacias informadas não existem ou estão inativas. A reportagem completa pode ser acessada através do link: http://azmina.com.br/2016/10/delegacias-da-mulher-so-existem-em-5-das-cidades-brasileiras/ 
amplamente. Céli Regina Pinto problematiza a cooptação das pautas feministas por políticos muitas vezes alheios aos direitos das mulheres; no entanto, ela afirma que:

[...] a importância dessa presença não está na sinceridade ou não dos candidatos em relação a seu comprometimento com as causas defendidas pelo movimento feminista, mas na percepção de que este é um tema relevante que pode dar votos, ou seja, existe um feminismo difuso na sociedade, fruto certamente de anos de militância do movimento organizado, que se expressa na presença da luta pelos direitos das mulheres em campanhas eleitorais. (PINTO, 2003, p. 93)

De fato, ao conseguir ser visibilizado e se fazer presente nas intenções políticas, o feminismo mostrou a sua relevância social; entretanto, o quadro político ainda não está favorável para as mulheres, uma vez que, mesmo havendo um sistema de cotas que garante $30 \%$ das candidaturas para as mulheres, esse número não chega a ser alcançado ou é preenchido por candidatas-fantasmas, ou seja, que não têm intenção de se elegerem (PINTO, 2003). Apesar da importância de se continuar lutando por mais representatividade política entre as mulheres, é fundamental compreender que existem outras formas, tão eficazes quanto, de fazer com que as reivindicações em prol dos direitos das mulheres sejam consideradas pelo Estado, como, por exemplo, as ONGs. É por esse meio que muitas mulheres têm se organizado e construído um espaço sólido para as reflexões e ações acerca dos problemas que afetam as mulheres brasileiras. A exemplo de ONGs que lutam pelas causas feministas podemos citar: o Centro Feminista de Estudos e Assessoria (CFEMEA); a Ações em Gênero, Cidadania e Desenvolvimento (AGENDE); a Articulação da Mulher Brasileira (AMB); a Rede Nacional Feminista de Saúde e Direitos Reprodutivos; a Geledés; entre outras.

São inúmeras as conquistas feministas que podem ser observadas nos dias atuais nos mais diversos contextos, desde as melhorias no mercado de trabalho até seu acesso aos domínios públicos. Com a ajuda dos avanços tecnológicos, principalmente no que se refere ao acesso à internet, as pautas feministas estão circulando de modo eficaz, fazendo com que cresça significativamente seu conhecimento entre as mulheres, sobretudo as mais jovens. Nunca se falou tanto a respeito das questões femininas. Entretanto, os direitos conquistados com muita luta foram se naturalizando, como se sempre tivessem existido, de modo que, o feminismo nem sempre é lembrado como sendo o principal responsável por eles.

Algumas teóricas, como é o caso da historiadora Margareth Rago, acreditam que estamos vivendo um momento pós-feminista. Em sua concepção, não se trata de um 
momento em que todas as conquistas feministas já foram alcançadas e concretizadas, ela entende o conceito de pós-feminismo "a partir da instauração de novas configurações nas problematizações e nas relações que se travam no interior desse movimento, quando um determinado patamar de reconhecimento social das questões femininas foi atingido" (RAGO, s/d, p. 1). Não é sobre o fim do feminismo que sua teoria disserta, mas sobre o posicionamento privilegiado das feministas em "dobrar-se sobre si mesmo" através da reflexão e da auto-crítica, construindo um espaço de revisão das suas representações e, sobretudo, colaborando para a "feminização cultural" (RAGO, 2001).

É em torno deste pensamento que Margareth Rago constrói sua teoria com base no conceito de filoginia. Por filógino entende-se o contrário de misógino, ou seja, "amigo das mulheres e do feminino, o que resulta decisivamente do aporte social e cultural das mulheres no mundo público" (RAGO, s/d, p. 3). O apelo feito por Margareth Rago, deste modo, corresponde ao modo como a cultura feminina, apesar da sua já comprovada relevância, tende a ser hostilizada pela cultura hegemônica, estritamente patriarcal, como se houvesse, por parte da sociedade, uma espécie de medo, fazendo com que suas questões estejam sempre sendo demonizadas ou tidas como menos importantes. Assim, ao pensar em cultura a partir de um olhar filógino, espera-se que haja uma ruptura na universalidade masculina, permitindo que outros padrões possam ser incorporados nas práticas culturais e sociais, e por este caminho outros grupos marginalizados poderão representar a si mesmos, longe da perspectiva unilateral e distorcida dos grupos dominantes (RAGO, 2001).

A ideia de feminização cultural proposta por Margareth Rago se relaciona com o pensamento teórico da crítica literária feminista, que apresenta uma perspectiva feminista sobre a literatura, intencionando refletir e confrontar os pensamentos canônicos estabelecidos paras as mulheres. A produção de conhecimento a respeito das questões das mulheres e do caráter revisionista dessas produções se dá a partir da década de 1990, quando o feminismo acadêmico começa a ganhar forças. $\mathrm{O}$ interesse acadêmico pelos estudos feministas, de acordo com Margareth Rago,

[...] permitiu inovar profundamente não apenas no reconhecimento da participação das mulheres nos processos históricos, mas na crítica à própria narrativa histórica, vista agora como produção sexuada ou generificada. [...] E daí perceberam-se praticamente as limitações dos conceitos masculinos, inscritos na lógica da identidade, para representar o "irrepresentável" e, nesse caso, para dar conta das experiências e práticas femininas ou de outros grupos sexuais. (RAGO, 2001, p. 64) 
Por muito tempo, as mulheres foram representadas através da perspectiva dos homens. Da medicina às artes, a mulher foi reduzida a simplismos, classificaram-na como tendo uma subjetividade que a aproximava da natureza e estabeleceram para ela uma identidade dócil, doméstica e submissa. Esse pensamento acerca da mulher foi naturalizado através de diversos dispositivos de poder manipulado por homens. Graças aos estudos feministas, as produções feitas pelos homens sobre as mulheres, ao longo das décadas, puderam ser revisadas e repensadas a partir da concepção feminina, retificando as limitações conceituais masculinas. Logo, as mulheres passaram a se representar e apresentar novos e irrestritos conceitos acerca da subjetividade feminina, permitindo a possibilidade de ressignificação identitária.

A crítica literária feminista, deste modo, propiciou que tal revisão fosse feita na literatura, garantindo que os arquétipos estereotipados construídos para as mulheres fossem questionados, descontruídos e ressignificados, a partir das suas vivências. Desta maneira, é possível afirmar que seu papel é tanto ideológico quanto teórico, uma vez que, ao mesmo tempo que utiliza a literatura para analisar e interpretar a condição feminina retratada, e através disso repensar acerca dos papéis sociais pré-estabelecidos, utiliza-se destas informações para construir um estudo acerca da mulher na literatura, seja como objeto de representação ou como escritora. Assim, a crítica feminista incentiva a manutenção deste espaço significativo, em que as mulheres podem, cada vez mais, escrever sobre si a partir de suas vivências e experiências e, sobretudo, refletir teoricamente sobre essas produções. Além disso, a crítica feminista contribui para a reflexão sobre o proposital apagamento do patrimônio cultural das mulheres e, através desse exercício, busca maneiras de resgatá-lo e nutri-lo.

Pensar neste lugar de mulher escritora enquanto agente de produção, no sentido de que seu exercício produz linguagens e sentidos específicos próprios da sua condição de gênero, é enveredar por outra discussão pertinente: a existência, ou não, de um nicho literário identificado como "literatura feminina". É muito comum que a maioria das atividades que foram majoritariamente exercidas por homens seja universalizadas como sendo masculinas por essência. Por esse motivo, por exemplo, não se fala em um time de futebol masculino; em uma bancada congressista masculina; uma banda masculina; ou uma literatura masculina. Contudo, o adjetivo feminino é sempre inserido quando uma mulher, ou um grupo de mulheres, decide exercer tais atividades. A questão da "literatura feminina" se dá, principalmente, ao comparar o modo como as mulheres, em particular as escritoras do século XIX, convergiam nas características de suas escritas, o que, de 
acordo com Lúcia Castello Branco (1991), se dava pelo caráter intimistas de suas produções.

A estética hegemônica da literatura era, sobretudo, de ordem patriarcal, e os modos de produção das mulheres partiam de uma estética própria, configurando-se em uma via de escape para a auto-identificação e representação de si. Lúcia Castello Branco (1991), ao dissertar sobre a existência, ou não, dessa escrita feminina, afirma a existência de certa peculiaridade na maneira de escrever das mulheres do século XIX, principalmente na maneira como esses textos se "distinguiam dos demais por possuírem um tom, uma dicção, um ritmo, uma respiração próprios" (BRANCO, 1991, p. 13). A autora, no entanto, logo justifica tais semelhanças:

[...] essas preferências são facilmente explicáveis por uma leitura de cunho sociológico: com um olhar histórico não é difícil afirmar que as mulheres não escreviam textos épicos porque não iam às guerras, que sua preferência pelo gênero memorialístico ou autobiográfico se deve ao seu profundo conhecimento dos universos do lar e do eu, próprios à criação de uma escrita intimista etc. etc. (BRANCO, 1991, p. 14)

Lúcia Castello Branco aponta, com esta afirmação, para a problemática questão da limitação social e cultural da mulher do século XIX. Restringida a espaços domésticos, com pouco, ou nenhum, conhecimento a respeito das esferas públicas e tendo que lidar com o cerceamento, a mulher escritora tinha como único instrumento sua própria experiência, que, pelos motivos citados, era limitada, considerando os espaços restritos ocupados por elas, e pouco interessava aos homens. É interessante notar que a hostilidade masculina pela escrita de autoria feminina se deu até um determinado momento; não que os homens tenham passado a admirar essa escrita, mas a cooptaram de tal modo que é possível observar que muitos livros direcionados para "donas de casa entediadas" são escritos por homens, o que vai ao encontro com o pensamento de Lúcia Castello Branco quando ela afirma que "[...] feminino aqui não se refere exclusivamente à mulher, mas tem a ver com a mulher, ainda que apenas de uma certa maneira, apenas em uma certa instância” (BRANCO, 1991, p. 15).

Com base nessa concepção, o problema que emerge sobre a questão da literatura feminina se expõe: a "literatura feminina", enquanto gênero literário, existe? Toda produção de autoria feminina se enquadra nesse nicho? Os estudos desenvolvidos por Lúcia Castello Branco nos inserem no cerne dessa contradição. Os gêneros literários são estabelecidos ou definidos obedecendo uma lógica de poder, antes exercida por críticos 
literários, hoje pelo mercado editorial em conjunto com a intenção do autor. Assim, fica evidente que o modo como as obras literárias são definidas diz muito sobre os mecanismos mercadológicos, mecanismos esses que visam o alcance de determinado grupo. Muitos aspectos são considerados no momento de eleger tal grupo focal, é nesse ponto que os estereótipos, arquétipos e estigmas políticos, sociais e culturais são explorados a fim de criar uma identificação entre obra e leitor. Não há dúvidas que essa lógica de poder está sob influência massiva de homens, uma vez que eles dominam as esferas de poder e, consequentemente, ditam os padrões hegemônicos tendo suas produções como parâmetro. Diante disso, é possível afirmar que não foram as autoras que construíram esse gênero literário a fim de divulgar ou valorizar suas produções, mas sim homens interessados em classificar e direcionar essas produções e, em seguida, se aproveitar de seu público consumidor.

Nesse contexto, podemos concordar com a existência da "literatura feminina" enquanto gênero literário, uma vez que essa categoria se inseriu no mercado e abrange uma série de critérios que legitimam sua existência. Todavia, é preciso reiterar que ela não é necessariamente uma produção exclusivamente feita por mulheres; o sexo ou gênero de quem a produz não interfere na sua constituição, pois, como visto, muitos autores homens passaram a produzir nesse nicho a fim de obterem vantagens, seja financeira ou social, com esse público tido como menos exigente. Isso nos leva a pensar que tal nicho literário trabalha a serviço da crença de que todas as mulheres se interessam pelo mesmo gênero literário, portanto, qualquer pessoa que domine a técnica da escrita e compreenda o "universo feminino", sendo este o conjunto de características e estereótipos naturalizados socialmente e culturalmente sobre as mulheres, está apto a agradar o, supostamente nada distinto, público feminino.

Bem como, não se pode afirmar que toda mulher escritora faça parte do gênero "literatura feminina", pois, tal classificação limita a criação artística de escritoras que produzem dentro de outros gêneros literários. Por essa razão, endossamos a importância de reconhecer a literatura de autoria feminina em toda sua vastidão, entendendo que esta pode encaixar-se nesse nicho, mas pode também ser totalmente divergente dele, uma vez que as mulheres expandiram seus limites de experiência e conhecimentos e manifestaram isso em suas produções. O título de "literatura feminina" indica o caráter misógino das instituições artísticas, que, ainda com a ideia da universalização do masculino, insistem em denominar menor tudo que foge de sua estética. Não se trata em concordar com a noção de que a "literatura feminina", seja produzida por quem for, esteja no rol da 
literatura de menor valor. O que reivindicamos, por meio dessa discussão, é a importância do processo de reconhecimento de si a partir do exercício de revisão e a legitimação da literatura de autoria feminina enquanto um espaço de representação e de representatividade, considerando sua capacidade de promover ressignificações, agenciar reinvenções e garantir a existência de mulheres com toda sua pluralidade.

\section{Referências}

BLAY, Eva Alterman. Como as mulheres se construíram como agentes políticas e democráticas: o caso brasileiro. In: Eva Alterman Blay; Lúcia Avelar. (Orgs.). 50 Anos de feminismo: Argentina Brasil e Chile. São Paulo: Edusp, Fapesp, 2017.

BRANCO, Lúcia Castello. O que é escrita feminina. São Paulo: Brasiliense, 1991 (Coleção Primeiros Passos).

PINTO, Céli Regina Jardim. Uma história do feminismo no Brasil. São Paulo: Editora Fundação Perseu Abramo, 2003. (Coleção história do povo brasileiro)

RAGO, Margareth. Feminizar é preciso: por uma cultura filógina. Disponível em: http://www.scielo.br/scielo.php?script=sci_arttext\&pid=S0102-88392001000300009 acessado em 28 de outubro de 2017.

RAGO, Margareth. Feminismo e subjetividade em tempos pós-modernos. Disponível em: http://www.historiacultural.mpbnet.com.br/feminismo/Feminismo_e_subjetividade.pdf acessado em 28 de outubro de 2017.

TELLES, Maria Amélia de Almeida. Breve história do feminismo no Brasil. São Paulo: Brasiliense, 1990. (Coleção tudo é história) 